\title{
Rescue of sorafenib-pretreated advanced hepatocellular carcinoma with tamoxifen
}

\author{
Margaret Ottaviano $^{1 *}$, Giovannella Palmieri ${ }^{1 *}$, Vincenzo Damiano ${ }^{1}$, Marianna Tortora $^{1}$ and Liliana Montella $^{2}$ \\ ${ }^{1}$ Department of Clinical Hematology, Oncology, Anatomy and Clinical Imaging, Rare Tumours Reference Center Oncology Unit, "Federico II" University of \\ Naples, Italy \\ ${ }^{2}$ Medical Oncology Unit, "San Giovanni di Dio” Hospital, Frattamaggiore, 80027 Naples, Italy
}

\begin{abstract}
Advanced hepatocellular carcinoma (HCC) is a tumor hard to treat because of cancer heterogeneity and underlying liver cirrhosis. Sorafenib has changed natural history producing overall survival benefit, however, progressing and/or intolerant patients have no available treatment apart palliative care until novel drugs will be put on the market. In this paper, we describe an experience with tamoxifen added to sorafenib in patients with advanced HCC at sorafenib progression.
\end{abstract}

Core Tip: A different voice tone is presented in this present report: despite tamoxifen was uniformly claimed as a useless drug, perhaps it could produce some clinical benefit at sorafenib progression in advanced hepatocellular carcinoma.

\section{Introduction}

Hepatocellular carcinoma (HCC) is the fifth most common cancer in the world and the second most common cause of cancer-related death [1]. The median survival for patients with early and advanced tumors without specific treatments is 6-9 months and 1-2 months, respectively. HCC develops mostly on chronic infected liver: in Africa and Asia HCC is mainly related to endemic hepatitis B virus (HBV) infection and aflatoxin B1 exposure, in Western countries and Japan $\mathrm{HCC}$ is related to hepatitis $\mathrm{C}$ virus $(\mathrm{HCV})$ infection and non-alcoholic steatohepatitis. Immune-mediated chronic inflammation in hepatitis promotes progressive fibrosis and development of liver cirrhosis, which themselves are early factors responsible for carcinogenesis. Persistent inflammation is known to promote carcinogenesis and increases tumor aggressiveness [2]. HCC is a clear example of inflammation-related cancer as more than $90 \%$ of HCCs arise in the context of hepatic injury and inflammation. Despite HCC might be potentially preventable with vaccination, antiviral treatments and active surveillance in patients infected by chronic hepatitis, HCC was still discovered in advanced stages.

Until now, sorafenib (multi-kinase inhibitor) has been the only systemic therapy with a demonstrated survival benefit in HCC. Two pivotal studies launched sorafenib in the global market as the most effective available drug in HCC. SHARP trial [3] reported a median overall survival of 10.7 months in the sorafenib group and 7.9 months in the placebo group (hazard ratio in the sorafenib group, $0.69 ; 95 \% \mathrm{CI}$ : $0.55-0.87 ; P<0.001)$. In Asia-Pacific trial median overall survival reported was 6.5 months (95\% CI 5.56-7.56) in patients treated with sorafenib, compared with 4.2 months (3.75-5.46) in those who received placebo (hazard ratio [HR] 0.68 [95\% CI 0.50-0.93]; $\mathrm{p}=0.014$ ) [4].

However, survival benefit reported with sorafenib is overall modest and the study population had a good to excellent performance status and Child-Pugh A score. As all clinicians know, in practice most patients with advanced HCC are unselected and have an advanced cirrhosis with a following worse Child-Pugh score [5]. Liver failure induced by cirrhosis progression and cancer is a major concern in the management of these patients. The unsuccessful medical treatment of HCC is, at least in part, due to complex molecular alterations present in HCC tissue and to the activation of multiple signal transduction pathways that control cell proliferation and tumor progression [6]. No effective treatments for patients with advanced HCC who are intolerant to sorafenib or who have progressed during sorafenib are available. The management of patients progressing on sorafenib is still a challenge and often only palliative care can be suggested due to fast deterioration of liver function and lack of cost-effective treatments in second lines.

Given the lack of available options at sorafenib progression, we investigate the role of tamoxifen in restore clinical activity of sorafenib in a series of HCC patients.

\section{Materials and methods}

Data from medical records of patients who were intolerant to or progressed during full dose sorafenib therapy $(800 \mathrm{mg} /$ daily $)$ and were treated with sorafenib (400 $\mathrm{mg}$ ) plus tamoxifen (40mg) were retrieved in this retrospective single center study. Patients were required to

Correspondence to: Giovannella Palmieri, Rare Tumours Reference Center Oncology Unit, “Federico II” University of Naples, Italy, Tel: 0039- 0817462114; Fax 0039- 0817462114; Email: giovpalm@unina.it

Margaret Ottaviano, Oncology Unit, Department of, Hematology, Oncology, Anatomy and Clinical Imaging, Rare Tumors Reference Center "Federico II" University of Naples, Via S. Pansini 5, 80131, Naples, Italy, Tel 0039- 0817462114; Fax 0039- 0817462114; Email: margaretottaviano@gmail.com

Key words: estrogen receptor, hepatocellular carcinoma; rescue, sorafenib, tamoxifen

Received: November 10, 2017; Accepted: November 27, 2017; Published: November 29, 2017 
have HCC confirmed by biopsy. Inclusion and exclusion criteria were described in Table 1. Patients underwent basal clinical evaluation, ECG, blood chemistry, analysis of liver function, $\alpha$-fetoprotein ( $\alpha$-FP) assay, whole body Computed Tomography, esophagogastroduodenoscopy, echocardiography, and other examinations if clinically required. Treatment was continued until disease progression or unacceptable toxicity.

Response to treatment was assessed using RECIST criteria (version 1.1) [7] every four months. At baseline, tumor lesions will be categorized measurable (lesions that can be accurately measured in at least one dimension [longest diameter to be recorded] as $\geq 20$ $\mathrm{mm}$ with conventional techniques or as $\geq 10 \mathrm{~mm}$ with spiral computed tomography (CT) scan) or no measurable (all other lesions, including small lesions [longest diameter $<20 \mathrm{~mm}$ with conventional techniques or $<10 \mathrm{~mm}$ with spiral CT scan] and truly no measurable lesions). All measurable lesions up to a maximum of 10 lesions in total should be identified as target lesions and recorded and measured at baseline. Taking into account the measurement of the longest diameter only for all target lesions, complete response (CR) was defined as the disappearance of all target lesions; partial response (PR) as at least a $30 \%$ decrease in the sum of the longest diameter of target lesions, taking as reference the baseline sum longest diameter; progressive disease (PD) as at least a $20 \%$ increase in the sum of the longest diameter of target lesions, taking as reference the smallest sum longest diameter recorded since the treatment started or the appearance of one or more new lesions; stable disease (SD) when neither sufficient shrinkage to qualify for partial response nor sufficient increase to qualify for progressive disease, taking as reference the smallest sum longest diameter since the treatment started. The disease-control rate (DCR) was defined as the percentage of patients who had a best-response rating of complete response, partial response, or stable disease (according to RECIST 1.1) that was maintained for at least 28 days after the first demonstration of that rating on the basis of independent radiologic review.

Median overall survival measured from the start of treatment, time to progression (TTP), overall response rate (ORR), median duration of treatment and disease control rate were assessed. Toxicity monitoring was performed every 28 days. Child-Pugh and ECOG Performance Status (PS) variations and alpha-fetoprotein changes during time were recorded as well.

Overall survival (OS) was calculated using the Kaplan-Meier method. To evaluate risk factors for survival in this series of HCC patients, univariate analysis was performed using the Kaplan-Meier method and evaluated using the log-rank test. Statistical analyses were performed using the SPSS software (ver. 18.0 for Windows; SPSS, Inc., Chicago, IL, United States). A P value $<0.05$ was considered to indicate statistical significance.

\section{Results}

Records of 25 patients treated with sorafenib $400 \mathrm{mg}$ plus tamoxifen $40 \mathrm{mg}$ from June 2009 to January 2017 were included in this analysis, Median age was 71 years old (range, 59-84). All patients but two were male. The median treatment duration was 11 months (range, 4-68). Patients details were available in Table 2 and 3.

Ten patients $(40 \%)$ were previously treated with local treatments: specifically, 4 patients underwent chemoembolization, 2 patients were treated with thermo-ablation, 1 patient received PEI (Percutaneous Ethanol Injection), 2 patients were treated with chemoembolization and radiofrequency, 1 patient underwent PEI, radiofrequency and liver transplantation followed by adjuvant capecitabine. All the patients
Table 1. Inclusion and Exclusion criteria.

Inclusion criteria

1.Patients of either sex aged $\geq 18$ years;

2.Histological diagnosis of $\mathrm{HCC}$;

3.Advanced disease not more susceptible to local/surgical treatments;

4. Eastern Cooperative (ECOG) Performance Status (PS) $\leq 2$;

5. Adequate haematological function: absolute neutrophil count $(\mathrm{ANC})>1.5 \times 109 / \mathrm{L}$, platelet count $>\geq$

100x109/1, haemoglobin $\geq 9 \mathrm{~g} / \mathrm{dL}$;

6. Adequate hepatic function: total bilirubin $<3 \mathrm{mg} / \mathrm{dL}$, albumin $>2.5 \mathrm{mg} / \mathrm{dL}$, aspartate transaminase (AST) and alanine transaminase (ALT) $<$ five times the superior limit of normal ranges;

7. Adequate renal function: serum creatinine $<2 \mathrm{mg} / \mathrm{dL}$, urinary protein $<500 \mathrm{mg} / 24$ h), amilases and lipases less than 1,5 times the superior limit of normal ranges;

8. International normalised ratio (INR) $<2.3$.

Exclusion criteria

1.Brain metastases or leptomeningeal disease;

2. Subject with fibrolamellar hepatocarcinoma or mixed cholangio-hepatocellular carcinoma;

3.Patients with a history of active bleeding, significant medical comorbidities, HIV infection, active untreated viral B hepatitis, ulcers or wounds not healing from three months, thyroid disease uncontrolled by medical therapies, clinically significant cardiovascular disease including uncontrolled hypertension, myocardial infarction and unstable angina, NYHA grade II or greater congestive heart failure, hyponatremia $(\leq 130 \mathrm{mMol} / \mathrm{L})$, serum levels of potassium $\leq 3.5 \mathrm{mMol} / \mathrm{L}$.

Table 2. Patient' characteristics. GOT $=$ Glutamic Oxaloacetic Transaminase GPT $=$ Glutamate-Pyruvate Transaminase; PT $\mathrm{INR}=$ prothrombin time International Normalized Ratio.

\begin{tabular}{|l|l|}
\hline No. of patients & 25 \\
\hline Median age (yrs) & $71,58( \pm 5,43 \mathrm{SD})$ \\
\hline Age range $(\mathrm{yrs})$ & $59-84$ \\
\hline Sex (male/female) & 23 male/ 2 female \\
\hline Aetiology of liver disease & \\
\hline -Hepatitis B & 2 \\
\hline -Hepatitis C & 17 \\
\hline -Coinfection B \& C & 1 \\
\hline -Ethanol abuse & 1 \\
\hline -Ethanol abuse \& HCV & 2 \\
\hline -Cryptogenic & 2 \\
\hline Child-Pugh grade & \\
\hline -Child-Pugh A & 10 \\
\hline -Child-Pugh B & 12 \\
\hline -Child-Pugh C & 3 \\
\hline Signs of portal hypertension & \\
\hline -partial/complete portal vein & 9 \\
\hline thrombosis & 8 \\
\hline -ascites & 5 \\
\hline -encephalopathy & 7 \\
\hline -esophageal varices & 0 \\
\hline Concomitant tumors & $3(1$ rectum, 1 prostate + rectum, 1 lung $)$ \\
\hline Tumor lesion & 2 \\
\hline -Single & 23 \\
\hline -Multiple & $11-90 \mathrm{~mm}$ \\
\hline -Tumor diameter (range, $\mathrm{mm})$ & 3 (distant), 9 (regional), 4 (dist + reg) \\
\hline -metastasis & $-1981,17 \mathrm{ng} / \mathrm{mL}$ \\
\hline Laboratory parameters & $-86,45 \mathrm{U} / \mathrm{L}$ \\
\hline -Alfa-fetoprotein (mean ng/mL) & $-71,6 \mathrm{U} / \mathrm{L}$ \\
\hline -GOT (mean U/L) & $-129,3$ \\
\hline -GPT (mean U/L) & -1.5 \\
\hline -Platelets (x10 $/ \mathrm{L})$ & \\
\hline - PT INR (INR) & \\
\hline
\end{tabular}

Table 3. Previous local treatment.

\begin{tabular}{|l|c|}
\hline & No. of patients \\
\hline Locoregional treatment & 10 \\
\hline -chemoembolization & 4 \\
\hline -thermo-ablation & 2 \\
\hline -PEI & 1 \\
\hline -Chemoembolization and radiofrequency & 2 \\
\hline -PEI, radiofrequency and liver transplantation & 1 \\
\hline followed by adjuvant capecitabine & \\
\hline
\end{tabular}

included in this series were treated with sorafenib conventional full dose as first line systemic therapy, stopped in 13 for progressive disease and 12 for intolerance.

At the time of the analysis (13rd January 2017), 2 patients are still on treatment with sorafenib (400mg) plus tamoxifen $(40 \mathrm{mg})$, and 
no patients discontinued treatment for adverse events. At the first radiological evaluation after four months of treatment, accordind to RECIST (version1.1), we recorded 4 PRs (16\%), 14 SD (56\%) and 7 PD (28\%). In two patients with PR, the recanalization of portal vein thrombosis was seen with a concomitant improvement of the ECOG PS from 2 to 0 . In figure 1 ( $a$ and $b$ ) a case of response to treatment with tamoxifen plus sorafenib was shown. Overall disease control rate $(\mathrm{CR}+\mathrm{PR}+\mathrm{SD})$ was $72 \%$. Median overall survival was 12 months (4-72 months) (Figure 2). Median time to progression (TTP) was 9 months (range 4-68) (Table 4 and 5).

No correlation was found between survival and locoregional treatments [Hazard ratio $=0.8376(0.3618-1.939), \mathrm{P}=0.654$ ] (Figure 3a), as well as aetiology (HCV versus no-HCV based tumor) [Hazard ratio= 0.8318 (0.3279-2.11), $\mathrm{P}=0.6668$ ] (Fugure 3b). Interestingly, correlation was found between survival and $\alpha$-FP reduction $(<50 \%$ versus $>50 \%)$ [Hazard ratio $=0.2871(0.0864-0.9542), \mathrm{P}=0.0008$ ] (Figure 3c).

Improvement of ECOG PS was obtained in 11 patients $(6$ patients from 1 to 0 , one patient from 2 to 1 and 4 patients from 2 to 0 ), of

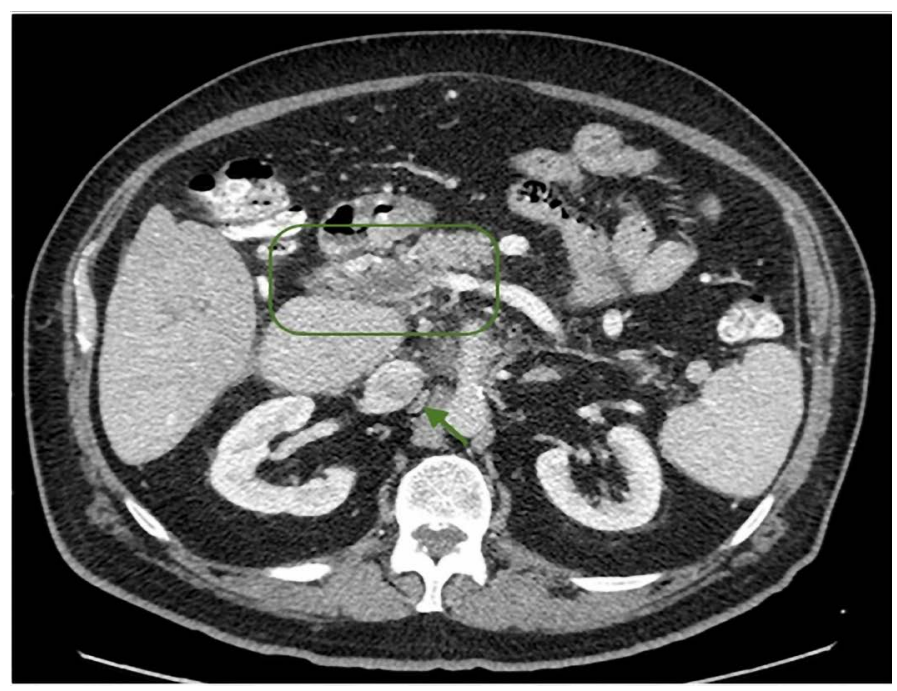

Figure 1a. Contrast Enhanced Computed Tomography image before starting Sorafenib+Tamoxifen

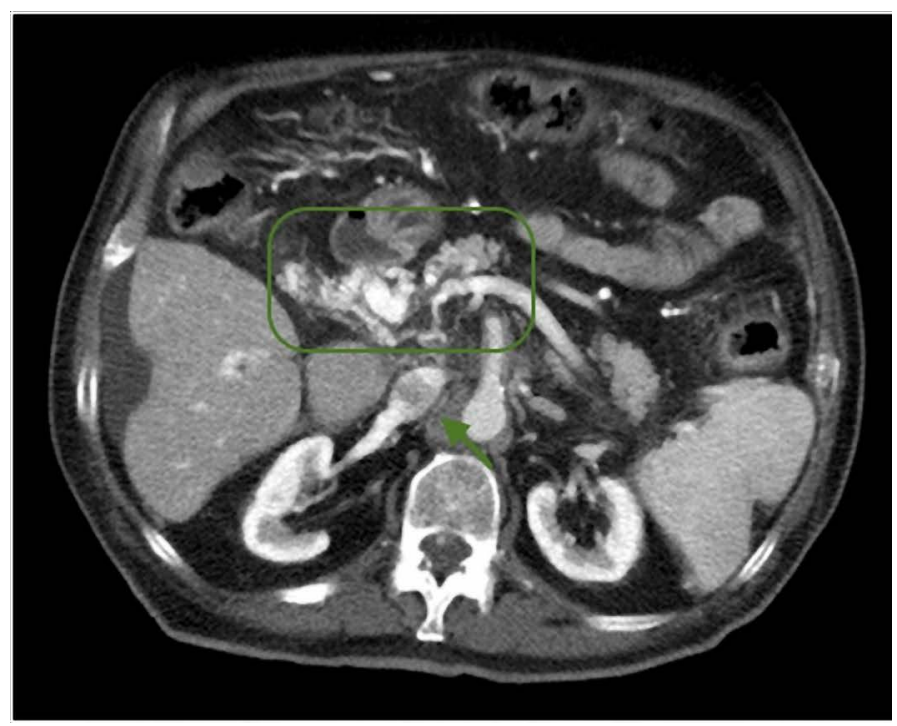

Figure 1b. Contrast Enhanced Computed Tomography image of portal vein thrombosis and inferior vena cava after treatment with Sorafenib+Tamoxifen.
mOS (12 months)

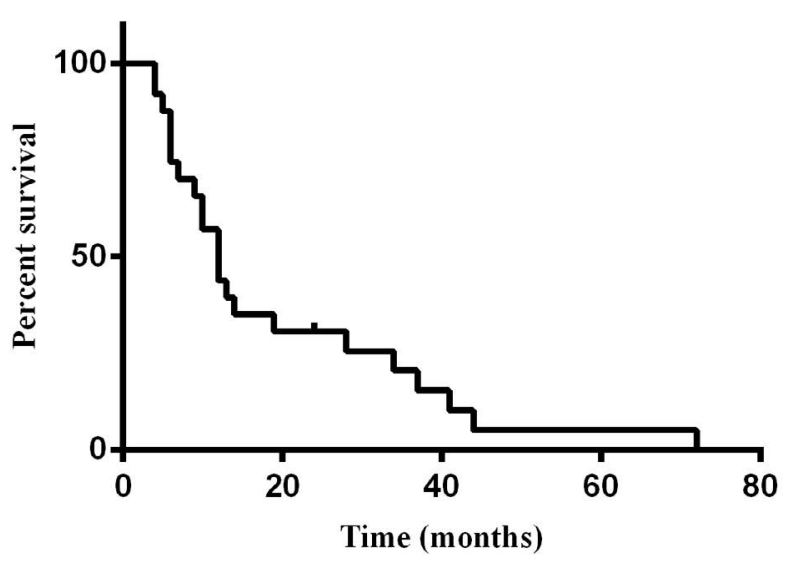

Figure 2. Overall survival curve.

Table 4. Sorafenib plus tamoxifen results. $\mathrm{CR}=$ complete response; $\mathrm{PR}=$ partial response; $\mathrm{SD}=$ stable disease; PD progression disease; $\mathrm{DCR}$ disease contol rate; TTP=time to progression.

\begin{tabular}{|c|c|}
\hline CR & $0 \%$ \\
\hline PR & $16 \%$ \\
\hline SD & $56 \%$ \\
\hline PD & $28 \%$ \\
\hline DCR (CR+PR+SD) & $72 \%$ \\
\hline Median TTP (95\% CI) months & $9.0(4-68)$ \\
\hline Median overall survival & 12 months (4-72) \\
\hline
\end{tabular}

whom one patient had an ECOG PS improvement from 1 to 0 although he had progressive disease at four months.

During study 8 patients improved Child-Pugh (5 patients from B to A class, one from $\mathrm{C}$ to $\mathrm{B}$ and two from $\mathrm{C}$ to $\mathrm{A}$ ). These patients had also the most elevated value of alpha-fetoprotein at study entry and at final analysis.

All patients showing PR, had $\alpha$-FP normalization and a longer survival. Treatment was generally well tolerated with no grade $3-4$ toxicities.

\section{Discussion}

This study started despite uninviting premises.

Tamoxifen did not show survival improvement in patients with advanced HCC in a large randomized trial [8]. Multiple study confirmed that tamoxifen has not to be considered for the treatment of HCC patients [9-11].

Defining progression in advanced HCC is difficult not only because assessment of disease response after antiangiogenic therapy is hard to define, but also because underlying cirrhosis significantly affects performance status and liver function.

Some data revealed that, despite progression, sorafenib similarly to other antiangiogenics could still work beyond progression $[12,13]$.

When our series of advanced HCC patients therapy started therapy with concomitant tamoxifen and sorafenib, no second line treatment for advanced HCC was available. Tamoxifen is easily accessible; therefore, we use sorafenib and tamoxifen in the effort to restore sorafenib sensitivity. In this study, we registered a significant response rate and survival given the advanced disease. Despite no quality of life study was performed, performance status improved with the addition of tamoxifen to sorafenib. 
Table 5. $\mathrm{M}=$ male; $\mathrm{F}=$ female; $\mathrm{NR}=$ no response; $\mathrm{PR}=$ partial response; $\mathrm{SD}=$ stable disease; $\mathrm{PD}=$ progressive disease.

\begin{tabular}{|c|c|c|c|c|c|c|c|c|c|}
\hline $\mathbf{N}$ & Sex & Age & Aetiology & Child & Basal aFP & $\begin{array}{c}\text { Response at } 4 \\
\text { months }\end{array}$ & $\begin{array}{l}\text { aFP at } 4 \\
\text { months }\end{array}$ & $\begin{array}{c}\text { Duration of } \\
\text { response } \\
\text { (months) }\end{array}$ & $\begin{array}{r}\text { Survival } \\
\text { (months) }\end{array}$ \\
\hline 1 & M & 61 & $\mathrm{HCV}$ & A & 985.7 & PR & 5 & 68 & 72 \\
\hline 2 & $\mathrm{M}$ & 69 & $\mathrm{HCV}$ & A & 3.4 & SD & 4.55 & 10 & 10 \\
\hline 3 & M & 77 & $\mathrm{HCV}$ & B & 58350.6 & PD & 70348 & NR & 4 \\
\hline 4 & M & 68 & $\mathrm{HCV}+\mathrm{HBV}$ & B & 8560 & PD & 10167 & NR & 4 \\
\hline 5 & M & 71 & $\mathrm{HCV}$ & A & 32 & SD & 20.6 & 12 & 19 \\
\hline 6 & $\mathrm{M}$ & 78 & $\mathrm{HCV}$ & A & 1931 & SD & 369 & 44 & 44 \\
\hline 7 & M & 61 & $\mathrm{HCV}$ & $\mathrm{C}$ & 10000 & PD & 13457 & NR & 6 \\
\hline 8 & $\mathrm{M}$ & 65 & $\mathrm{HCV}$ & B & 793.2 & PD & 602.3 & NR & 9 \\
\hline 9 & M & 73 & $\mathrm{HCV}+\mathrm{ALC}$ & A & 41.2 & SD & 130 & 13 & 13 \\
\hline 10 & $\mathrm{M}$ & 68 & HBV & A & 7.9 & SD & 5.68 & 10 & 14 \\
\hline 11 & M & 59 & $\mathrm{HCV}$ & A & 6.8 & SD & 5.4 & 7 & 12 \\
\hline 12 & $\mathrm{M}$ & 70 & CRYPTO & B & 7076 & PR & 0.7 & 28 & 28 \\
\hline 13 & $\mathrm{M}$ & 79 & $\mathrm{HCV}$ & $\mathrm{C}$ & 49.5 & PR & 6.9 & 41 & 41 \\
\hline 14 & $\mathrm{M}$ & 64 & $\mathrm{HCV}$ & B & 348 & SD & 329 & 6 & 6 \\
\hline 15 & M & 77 & $\mathrm{HCV}$ & B & 6.7 & PD & 9.0 & NR & 5 \\
\hline 16 & $\mathrm{M}$ & 62 & $\mathrm{HCV}+\mathrm{ALC}$ & A & 52,2 & SD & 26.5 & 37 & 37 \\
\hline 17 & $\mathrm{M}$ & 73 & $\mathrm{HCV}$ & A & 1549 & SD & 400 & 8 & 10 \\
\hline 18 & $\mathrm{M}$ & 83 & $\mathrm{HCV}$ & $\mathrm{C}$ & 6414 & PR & 2.1 & 34 & 34 \\
\hline 19 & $\mathrm{M}$ & 71 & $\mathrm{HCV}$ & A & 82.61 & SD & 62.59 & 7 & 7 \\
\hline 20 & $\mathrm{M}$ & 77 & ALCOHOL & B & 3450 & SD & 2238 & ONGOING & ALIVE \\
\hline 21 & $\mathrm{M}$ & 75 & CRYPTO & B & 3276.04 & SD & 400 & 6 & 6 \\
\hline 22 & $\mathrm{M}$ & 71 & $\mathrm{HCV}$ & B & 207.4 & PD & 2840 & NR & ALIVE \\
\hline 23 & $\mathrm{~F}$ & 84 & $\mathrm{HCV}$ & B & 5.74 & SD & 6.83 & ONGOING & ALIVE \\
\hline 24 & F & 76 & HBV & B & 82 & SD & 5.71 & 12 & 12 \\
\hline 25 & $\mathrm{M}$ & 67 & $\mathrm{HCV}$ & B & 71.03 & PD & 210 & NR & 12 \\
\hline
\end{tabular}

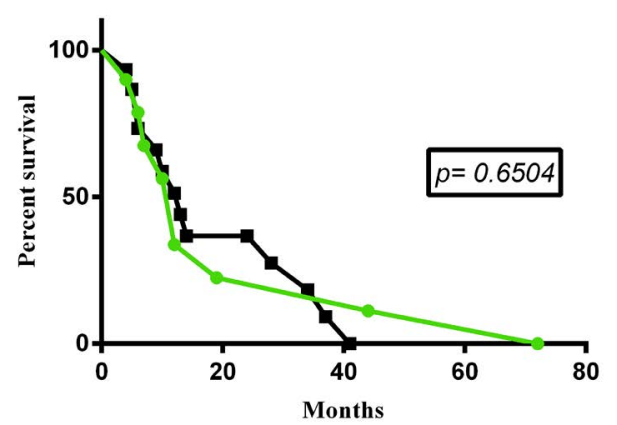

Figure 3a. Correlation between survival and locoregional treatments.

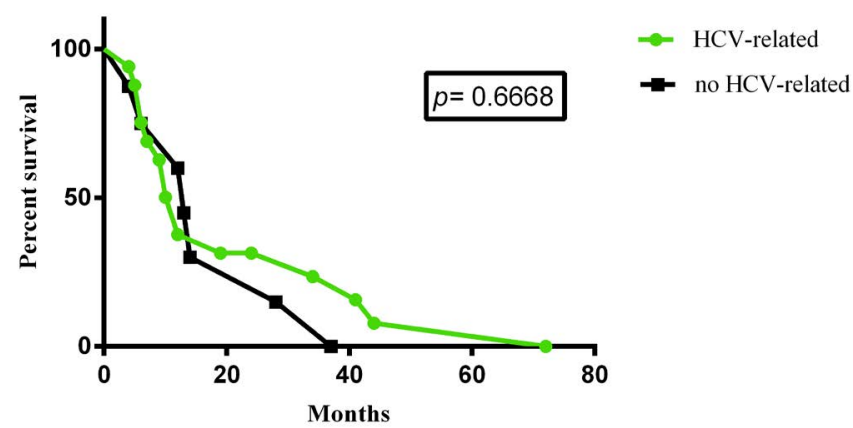

Figure 3b. Correlation between survival and aetiology.

Some survival benefit was recognized in patients without major hepatic insufficiency treated with tamoxifen also in the largest randomized trial, which claims that tamoxifen is useless. A biologic background sustains use of tamoxifen. Liver is a hormone-sensitive organ and therefore is influenced by gonadal hormones, such as estrogen [14]. Several studies suggest a relationship between sex hormones receptors and HCC. Estrogen receptors are expressed in different types of liver tissue from normal liver throughout the different stages of liver disease until cancer [15]. Elevated aromatase expression has been detected in hepatitis and HCC [16]. Estrogen

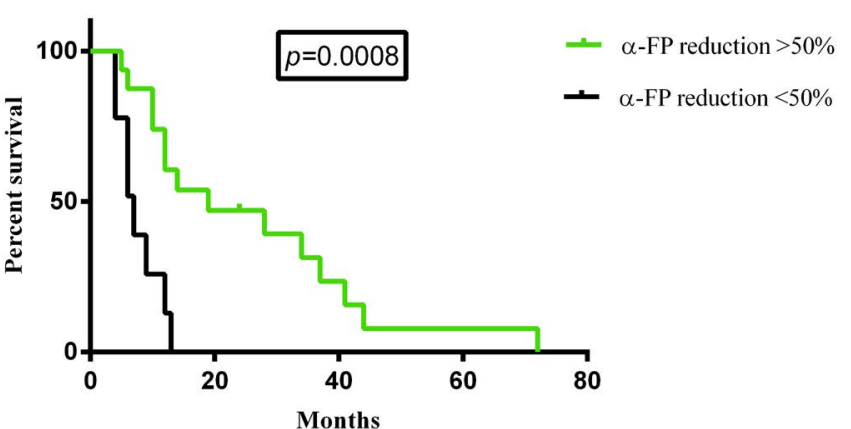

Figure 3c. Correlation with $\alpha$-FP reduction.

acts through estrogen receptor alpha (ER $\alpha)$ and estrogen receptor beta $(\operatorname{ER} \beta)$, that belong to a family of nuclear receptors that may regulate the expression of many genes [16]. ERa is a good mediator of cell proliferation, especially in breast cancer cells, driving cell proliferation in the presence of estrogen [17]. ER $\beta$ contrasts ERa and inhibits ERa mediated proliferation in many cells. Wild type ER (ER-66) appears decreased in HCC in favor of different isoforms, in particular ER-36, generating by alternative splicing [18]. ER-a seems to lose function during liver disease progression, and dysfunctional ER- $a$ could contribute to HCC development. In addition, ER $\alpha-36$ negatively regulates the transcriptional activity of ER-66 and ER- $\beta$ [16]. This crosstalk between ER subtypes forms a part of the complex ER signalling and has yet to be confirmed in HCC. However, variant ER- $\alpha$ is considered a predictor of poor prognosis both in HCC and breast cancer [16]. Estrogen are known to influence fibrosis in several tissues and may also influence evolution to cirrhosis. Given the association between estrogen and liver cancer, an eventual role of tamoxifen in the treatment of inoperable HCC has been suggested. The antiestrogenic compound tamoxifen has been shown to reduce the level of estrogen receptors in the liver, and to inhibit both hepatocyte proliferation after partial hepatectomy and HCC cell growth even through an estrogenreceptor-independent mechanism [15]. In contrast with previous evidence suggesting a potential benefit from antiestrogen treatments, an anti-inflammatory and immunoregulatory role of estrogen has been 
highlighted. In detail, there is also a different profile between estrogen receptors, being ER- $\beta$ related to strong anti-proliferative and antiinflammatory properties $[16,19]$. Several hypotheses were proposed to explain the failures of using anti-estrogen in treating HCC, including the dysfunction induced by variant ER- $\alpha$ (vER- $\alpha)$, regulation by the postreceptor signalling pathway and treatment with an insufficient therapy dose [16].

Tamoxifen itself is a prodrug, having relatively little affinity for ER. It is metabolized in the liver by the cytochrome

P450 isoform CYP2D6 and CYP3A4 into active metabolites such as 4-hydroxytamoxifen (4-OHT) (afimoxifene) and N-desmethyl-4hydroxytamoxifen (endoxifen) which have 30-100 times more affinity with the ER than tamoxifen itself. 4-OHT binds to ER competitively (with respect to the endogenous agonist estrogen) in tumor cells and other tissue targets, producing a nuclear complex that decreases DNA synthesis and inhibits estrogen effects. It is a nonsteroidal agent with potent antiestrogenic properties which compete with estrogen for binding sites in breast and other tissues. Tamoxifen causes cells to remain in the G0 and G1 phases of the cell cycle, therefore it is a cytostatic rather than cytocidal drug.

Until the advent of second-line effective and authorized treatments - first in class regorafenib - management of patients progressing on sorafenib should be relied only on palliative therapy or clinical trials where available. Chemotherapeutic agents were used in second-line with evidence of some activity [20]. Other suggested strategies are increasing drug dose [21], combination with agents affecting alternative disease pathways, switching to an alternative agent [22]. Concerning sorafenib dose increase, the published data did not document an impact on overall survival and potential toxicity arouse concern. Low dose sorafenib conversely can still maintain activity as some studies reported [23-26].

In general, when a patient with advanced HCC progressed on sorafenib, decline of performance status is considered a criterion to address patient to best supportive care. In our study performance status improvement was documented after addition of tamoxifen. Given the retrospective nature of the study and the limited number of patients, no conclusion can be made. However, where other options were lacking, tamoxifen plus sorafenib could produce interesting results. Prolonged disease control was not related to slowly tumor growing as these patients were all progressed during therapy with sorafenib alone. Briefly, the present case series describes an experience with tamoxifen associated to sorafenib at sorafenib progression. In the context of difficult management of HCC in clinical practice where not all is guidelinestrictly-referred systematically reflects in better results, the results reported with sorafenib plus tamoxifen can represent a fair chance.

\section{Author contributions}

Giovannella Palmieri, Margaret Ottaviano and Vincenzo Damiano collected patients' clinical data and performed the analysis, Marianna Tortora processed data and Liliana Montella revised the data and wrote the paper.

\section{Conflict-of-interest statement}

No conflict of interest.

\section{Institutional review board statement}

The study was reviewed and approved by "Federico II" University of Naples Ethical Committee.

\section{Informed consent statement}

All study participants, or their legal guardian, provided informed written consent prior to study enrollment.

\section{References}

1. Montella L, Palmieri G, Addeo R, Del Prete S (2016) Hepatocellular carcinoma: Wil novel targeted drugs really impact the next future? World J Gastroenterol 22: 6114 6126. [Crossref]

2. Nikolaou K, Sarris M, Talianidis I (2013) Molecular pathways: the complex roles of inflammation pathways in the development and treatment of liver cancer. Clin Cancer Res 19: 2810-2816. [Crossref]

3. Llovet JM, Ricci S, Mazzaferro V, Hilgard P, Gane E, et al. (2008) Sorafenib in advanced hepatocellular carcinoma. $N$ Engl J Med 359: 378-390. [Crossref]

4. Cheng AL, Kang YK, Chen Z, Tsao CJ, Qin S, et al. (2009) Efficacy and safety of sorafenib in patients in the Asia-Pacific region with advanced hepatocellular carcinoma: a phase III randomised. [Crossref]

5. Montella L, Addeo R, Caraglia M, Del Prete S (2010) Latest developments in targeted therapy for hepatocellular carcinoma. Expert Rev Anticancer Ther 10: 1635-1646.

6. Thomas MB1, Abbruzzese JL (2005) Opportunities for targeted therapies in hepatocellular carcinoma. J Clin Oncol 23: 8093-8108. [Crossref]

7. Eisenhauera EA,Therasseb P, Bogaertsc J, Schwartzd L H, Sargente D, et al. (2009) New response evaluation criteria in solid tumours: Revised RECIST guideline (version 1.1). European Journal of Cancer 45: 228-47.

8. Barbare JC, Bouché O, Bonnetain F, Raoul JL, Rougier P, et al. (2005) Randomized controlled trial of tamoxifen in advanced hepatocellular carcinoma. J Clin Oncol 23: 4338-4346. [Crossref]

9. Gallo C, De Maio E, Di Maio M, Signoriello G, Daniele B, et al. (2006) Tamoxifen is not effective in good prognosis patients with hepatocellular carcinoma. BMC Cancer 6: 196. [Crossref]

10. Nowak AK, Stockler MR, Chow PK, Findlay M (2005) Use of tamoxifen in advancedstage hepatocellular carcinoma. A systematic review. Cancer 103: 1408-1414. [Crossref]

11. Nowak A, Findlay M, Culjak G, Stockler M (2004) Tamoxifen for hepatocellular carcinoma. Cochrane Database Syst Rev: CD001024. [Crossref]

12. Raoul JL, Adhoute X, Gilabert M, Edeline J (2016) How to assess the efficacy or failure of targeted therapy: Deciding when to stop sorafenib in hepatocellular carcinoma. World J Hepatol 8: 1541-1546. [Crossref]

13. He AR, Goldenberg AS (2013) Treating hepatocellular carcinoma progression following first-line sorafenib: therapeutic options and clinical observations. Therap $A d v$ Gastroenterol 6: 447-458. [Crossref]

14. Baldissera VD, Alves AF, Almeida S, Porawski M, Giovenardi M (2016) Hepatocellular carcinoma and estrogen receptors: Polymorphisms and isoforms relations and implications. Med Hypotheses 86: 67-70. [Crossref]

15. Barbare JC, Bouché O, Bonnetain F, Raoul JL, Rougier P, et al. (2005) Randomized controlled trial of tamoxifen in advanced hepatocellular carcinoma. J Clin Oncol 23 . 4338-4346. [Crossref]

16. Shi L, Feng Y, Lin H, Ma R, Cai X1 (2014) Role of estrogen in hepatocellular carcinoma: is inflammation the key? J Transl Med 12: 93. [Crossref]

17. Shanle EK1, Xu W (2010) Selectively targeting estrogen receptors for cancer treatment Adv Drug Deliv Rev 62: 1265-1276. [Crossref]

18. Villa E, Grottola A, Colantoni A, De Maria N, Buttafoco P, et al. (2002) Hepatocellular carcinoma: role of estrogen receptors in the liver. Ann N Y Acad Sci 963: 37-45. [Crossref]

19. Monteiro R, Teixeira D, Calhau C (2014) Estrogen signaling in metabolic inflammation Mediators Inflamm 2014: 615917. [Crossref]

20. Granito A, Marinelli S, Terzi E, Piscaglia F, Renzulli M, et al. (2015) Metronomic capecitabine as second-line treatment in hepatocellular carcinoma after sorafenib failure. Dig Liver Dis 47: 518-522. [Crossref]

21. Pressiani T, Boni C, Rimassa L, Labianca R, Fagiuoli S, et al. (2013) Sorafenib in patients with Child-Pugh class A and B advanced hepatocellular carcinoma: a prospective feasibility analysis. Ann Oncol 24: 406-411. [Crossref]

22. He AR, Goldenberg AS (2013) Treating hepatocellular carcinoma progression following first-line sorafenib: therapeutic options and clinical observations. Therap $A d v$ Gastroenterol 6: 447-458. [Crossref] 
23. Nishikawa H, Osaki Y, Endo M, Takeda H, Tsuchiya K, et al. (2014) Comparison of standard-dose and halfầ $€^{\prime}$ dose sorafenib therapy on clinical outcome in patients with unresectable hepatocellular carcinoma in field practice: A propensity score matching analysis. Int J Oncol 45: 2295-2302. [Crossref]

24. Montella L, Addeo R, Cennamo G, Vincenzi B, Palmieri R, et al. (2013) Sorafenib in elderly patients with advanced hepatocellular carcinoma: a case series. Oncology 84: 265-272. [Crossref]
25. Iavarone M, Cabibbo G, Piscaglia F, Zavaglia C, Grieco A, et al. (2011) Field-practice study of sorafenib therapy for hepatocellular carcinoma: a prospective multicenter study in Italy. Hepatology 54: 2055-2063. [Crossref]

26. Morimoto M, Numata K, Kondo M, Kobayashi S, Ohkawa S, et al. (2015) Field practice study of half-dose sorafenib treatment on safety and efficacy for hepatocellular carcinoma: A propensity score analysis. Hepatol Res 45: 279-287. [Crossref]

Copyright: $(02017$ Ottaviano M. This is an open-access article distributed under the terms of the Creative Commons Attribution License, which permits unrestricted use, distribution, and reproduction in any medium, provided the original author and source are credited. 